\title{
Phase angle as a screening method for sarcopenia in community-dwelling older adults
}

\author{
Ângulo de fase como método de triagem \\ para sarcopenia em idosas \\ ativas de comunidade
}

\author{
Lidiane Barbosa SANTIAGO1 ${ }^{1}$ D 0000-0003-2587-0806 \\ Anna Karla Carneiro RORIZ1 1 (D) 0000-0002-1768-5646 \\ Carolina Cunha de OLIVEIRA2 (iD) 0000-0003-1196-0683 \\ Tatiane Melo de OLIVEIRA3 ${ }^{3}$ (D) 0000-0001-7938-9351 \\ Maria Ester Pereira da CONCEIÇÃO-MACHADO' (D) 0000-0001-5982-4213 \\ Lilian Barbosa RAMOS1 (iD) 0000-0002-2357-7377
}

\section{Objective}

We investigated the utility of the phase angle as a screening tool for sarcopenia.

\section{Methods}

We performed a cross-sectional study that included 169 active community-dwelling elderly women. The phase angle was determined using tetrapolar bioelectrical impedance, and sarcopenia was diagnosed based on skeletal muscle mass, muscle strength, and physical performance using bioelectrical impedance analysis, a handheld dynamometer, and

\footnotetext{
1 Universidade Federal da Bahia, Escola de Nutrição, Programa de Pós-Graduação em Alimentos, Nutrição e Saúde. R. Basilio da Gama, s/n., Canela, 40110-907, Salvador, BA, Brasil. Correspondence to: LB SANTIAGO. E-mail: <lidisantiagonutri@gmail.com>.

2 Universidade Federal de Sergipe, Departamento de Nutrição. Lagarto, SE, Brasil.

3 Universidade Estadual de Campinas, Faculdade de Ciências Médicas, Programa de Pós-Graduação de Gerontologia. Campinas, SP, Brasil.

Support: Programa de Apoio a Jovens Professores Doutores - PROPESQ (Edital: PROPCI/PROPG 04/2016).

Article elaborated from dissertation by L.B. SANTIAGO, entitled "Ângulo de fase e sarcopenia em idosas de comunidade" Universidade Federal da Bahia; 2021.
}

How to cite this article

Santiago LB, Roriz AKC, Oliveira CC, Oliveira TM, Conceição-Machado MEP, Ramos LB; Phase angle as a screening method for sarcopenia in community-dwelling older adults. Rev Nutr. 2022;35:e200243. https://doi.org/10.1590/1678-9865202235200243 
the gait speed test, respectively. Receiver operating characteristic curve analysis was performed to investigate the role of the phase angle as a predictor of sarcopenia.

\section{Results}

The prevalence of sarcopenia was $12.4 \%$. The median phase angle was $5.30^{\circ}$; elderly women with sarcopenia had lower phase angles than those without sarcopenia $(p=0.006)$. The phase angle cutoff for the detection of sarcopenia was $\leq 5.15^{\circ}$, with an area under the curve of 0.685 , sensitivity $81.0 \%$, specificity $60.8 \%$, and accuracy $63.31 \%$. Elderly women with a low phase angle show a high risk of presenting with reduced muscle mass.

\section{Conclusion}

The phase angle was shown to be a useful screening tool in elderly women with sarcopenia.

Keywords: Aged. Electric Impedance. Sarcopenia.

\section{R E S U M O}

\section{Objetivo}

Avaliar o ângulo de fase como método de triagem para sarcopenia.

\section{Métodos}

Estudo transversal realizado com 169 idosas ativas de comunidade. O ângulo de fase foi obtido por bioimpedância elétrica tetrapolar e a sarcopenia foi diagnosticada a partir da massa muscular esquelética, força muscular e performance fisica utilizando bioimpedância elétrica, dinamometria manual e o teste de velocidade de marcha, respectivamente. A curva Receiver Operating Characteristic foi construída para avaliar o ângulo de fase como preditor de sarcopenia.

\section{Resultados}

A prevalência de sarcopenia foi de 12,4\%. A mediana do ângulo de fase foi de 5,30; idosas com sarcopenia apresentaram valores menores do ângulo de fase em relação às não sarcopênicas $(p=0,024)$. O ponto de corte do ângulo de fase para identificar sarcopenia foi $\leq 5,15^{\circ}$, com área sob a curva de 0,685, sensibilidade de $81,0 \%$, especificidade de $60,8 \%$ e acurácia de 63,31\%. Observou-se que idosas com ângulo de fase reduzido apresentaram maior chance de terem massa muscular reduzida e sarcopenia.

\section{Conclusão}

O ângulo de fase se mostrou útil para triagem de idosas com sarcopenia.

Palavras-chave: Idoso. Impedância Elétrica. Sarcopenia.

\section{N T R O D U TIO N}

Sarcopenia is a muscle disease that is associated with an increased risk of falls, fractures, and mortality, which compromise the quality of life in elderly individuals [1-3]. Prevention and early diagnosis enable prompt interventions, which can improve survival of elderly individuals affected by sarcopenia [4].

Sarcopenia is diagnosed based on tests that evaluate muscle strength, muscle mass, and physical performance [1]. Therefore, preserved functional capacity is important to enable appropriate testing for accurate diagnosis of sarcopenia in elderly individuals [5]. Furthermore, modalities and equipment including computed tomography, magnetic resonance imaging, and dual-energy X-ray absorptiometry that are necessary to measure muscle mass and a dynamometer to measure muscle strength may not be widely available in routine clinical practice [1].

Estimation of the phase angle is a linear method used to determine the association between reactance (affected by tissue hydration) and resistance (affected by cell membrane integrity) measured using Bioelectrical Impedance Analysis (BIA) [6]. The phase angle is known to be correlated with many 
health conditions. It is considered a predictor of negative outcomes and is associated with muscle mass and strength and is shown to be an indicator of sarcopenia in institutionalized and hospitalized elderly patients [5,7-9]. However, its role in active community-dwelling elderly women remains unclear.

It is important to identify simple and cost-effective indicators of sarcopenia to facilitate early diagnosis and prompt intervention. Therefore, in this study, we investigated the utility of the phase angle as a screening tool for sarcopenia in active community-dwelling elderly women.

\section{METHODS}

This cross-sectional study included elderly women recruited from the three Open Universities of the Third Age of Salvador, Bahia, Brazil, which represents $75 \%$ of the universities of the city.

Elderly women ( $\geq 60$ years) who enrolled the universities and could undergo the necessary testing for diagnosis of sarcopenia were enrolled in the study. We excluded patients with implantation of cardiac pacemakers, aneurysm clips, or metallic devices of any type to avoid interference with the results of BIA.

With regard to sample calculation, the total number of elderly women who visited the universities was 408; the prevalence of sarcopenia was $15.4 \%$, the sampling error was $5 \%$, confidence level $95 \%$, and we added $10 \%$ for possible losses to follow-up or refusal to participate in the study [10]. Therefore, the estimated minimum sample size was 149 elderly women. Owing to the small numbers $(n=7)$ who enrolled these universities, we did not include men in the study.

The study was approved by the Research Ethics Committee of the Nutrition School of the Federal University of Bahia, assent 1.159.885/2015/12. All participants signed an informed consent form.

The phase angle was calculated following BIA using the Biodynamics ${ }^{\circledR}$ tetrapolar device, model 450 (Biodynamics Corp. Seattle, WA, USA). We used the following formula proposed by Baumgartner, Chumlea, and Roche [11]: phase angle (degrees)=tangent arc of reactance/resistancex180/ש.

Bioelectrical impedance analysis was performed based on the protocol recommended by Kyle et al. [12].

Sarcopenia was diagnosed based on the algorithm proposed by the Sarcopenia: revised European consensus on definition and diagnosis, which measures muscle strength, Skeletal Muscle Mass (SMM), and physical performance [1].

Using a portable hand-held dynamometer (Sammons Preston Smedley) with a gradation scale from 0 to $100 \mathrm{~kg} / \mathrm{strength}(\mathrm{kg} / \mathrm{f})$, we measured handgrip strength as an indicator of muscle strength. Two maximum attempts were made with each hand (dominant and non-dominant) to produce maximum voluntary handgrip strength, with a one-minute rest between them. The highest mean value was considered for analysis [13].

Muscle mass was measured using the Skeletal Muscle Index (SMI) derived using the following formula $\mathrm{SMI}=\mathrm{SMM} /$ height $^{2}$ [14]. The SMM was calculated based on the following formula proposed by Janssen et al. [14]: SMM $(\mathrm{kg})=$ Height $^{2}(\mathrm{~cm}) /$ resistance $(\mathrm{ohm}) \times 0.401+(0 \times 3.825)+($ age $[$ years] $\times-0.071+5.102)$. Resistance was measured using BIA.

Physical performance was measured using the gait speed in $\mathrm{m} / \mathrm{s}$. This test involved walking a distance of $4 \mathrm{~m}$ over a flat and straight surface at the usual walking speed. The time required to cover the distance was measured [15].

Components of sarcopenia were evaluated based on the first quartile of the sample. Reduced muscle strength (handgrip strength $\leq 18.75 \mathrm{~kg} / \mathrm{f}$ ) was considered the criterion to define sarcopenia; sarcopenia was 
diagnosed as reduced muscle strength and mass (handgrip strength $\leq 18.75 \mathrm{~kg} / \mathrm{f}$ and $\mathrm{SMI} \leq 6.41 \mathrm{~kg} / \mathrm{m}^{2}$ ), and severe sarcopenia was defined as a reduction in the three components (handgrip strength $\leq 18.75 \mathrm{~kg} / \mathrm{f}$, SMI $\leq 6.41 \mathrm{~kg} / \mathrm{m}^{2}$, and gait speed $\leq 0.77 \mathrm{~m} / \mathrm{s}$ ).

The body mass index was calculated using the following equation: weight/height ${ }^{2}$ and was analyzed as a continuous variable. The physical activity level was determined using a structured questionnaire; the variable used was categorically analyzed (yes or no).

Data normality was analyzed using the Kolmogorov-Smirnov test and homogeneity of variance using Levene's test. Descriptive analyses were presented as measures of central tendency, dispersion, absolute numbers, and frequencies.

The Kruskal-Wallis test was used to determine the various phase angle values across different categories of sarcopenia. The Mann-Whitney test was used for pair-wise comparison of categories in cases of a statistically significant difference.

A Receiver Operating Characteristic (ROC) curve was constructed using a positive diagnosis of sarcopenia as a reference; we estimated the sensitivity (sens), specificity (spec), and Area Under the Curve (AUC) with a confidence interval of $95 \%$. The following diagnostic accuracy measures were also used to investigate the utility of the phase angle as a diagnostic tool for sarcopenia: negative and positive predictive values, the Youden index, and accuracy. The cutoff value that produced the best combination of sens and spec was selected as the most appropriate value of the phase angle as an indicator of sarcopenia.

Logistic regression models (crude and adjusted for age and physical activity) were used to confirm the association between muscle mass, muscle strength, physical performance, and sarcopenia with the phase angle cutoff point determined using the ROC curve.

All statistical analyses were performed using the SPSS software, Windows version 21.0 (SPSS, Inc., Chicago, IL, USA). A p-value $<0.05$ was considered statistically significant for all statistical analysis.

\section{RE S U LTS}

Our study included 169 active community-dwelling elderly women (median age 69 years). The prevalence of sarcopenia and severe sarcopenia was $12.4 \%$ and $6.5 \%$, respectively. The median phase angle in this study was $5.30^{\circ}$ (Table 1 ).

The phase angles were lower in elderly women with sarcopenia than in those without sarcopenia $(p=0.006)$. Subcategory analysis showed that the differences remained statistically significant in the

Table 1 - Characteristics of community-dwelling elderly women.

\begin{tabular}{lc}
\hline Variables & \\
\hline Age (years) - Median (IQ) & $69(65.5-74.0)$ \\
Practitioners of physical activity - $\mathrm{n}(\%)$ & $143(84.6)$ \\
BMI $\left(\mathrm{kg} / \mathrm{m}^{2}\right)$ - Mean (SD) & $27.40(4.3)$ \\
Without sarcopenia - $\mathrm{n}(\%)$ & $125(74.0)$ \\
Probable sarcopenia - $\mathrm{n}(\%)$ & $23(13.6)$ \\
With sarcopenia - $\mathrm{n}(\%)$ & $10(5.9)$ \\
Severe sarcopenia $-\mathrm{n}(\%)$ & $11(6.5)$ \\
Phase Angle $\left(^{\circ}\right)-$ Median (IQ) & $5.30(4.80-5.80)$ \\
\hline
\end{tabular}

Nota: BMI: Body Mass Index, IQ= Interquartile Range, $\mathrm{SD}=$ Standard Deviations. 
non-sarcopenia and severe sarcopenia groups $(p=0.001)$ and between elderly women with probable and severe sarcopenia $(p=0.001)$ (Table 2 ).

The cutoff value that showed good diagnostic accuracy for sarcopenia in elderly women was $\leq 5.15^{\circ}$ (sens $81.0 \%$, spec $60.8 \%$ ) based on the area under the ROC curve (Figure 1). The cutoff point showed negative and positive predictive values and accuracy of $95.74 \%, 22.67 \%$, and $63.31 \%$, respectively. The Youden index was 0.418.

Table 2 - Median difference of phase angle between categories of sarcopenia in community-dwelling elderly women.

\begin{tabular}{|c|c|c|c|}
\hline \multirow{2}{*}{ Variables } & \multicolumn{3}{|c|}{ Phase Angle $\left(^{\circ}\right)$} \\
\hline & Median & IQ & $p$-value \\
\hline Without sarcopenia & 5.40 & $(4.90-5.90)$ & \multirow{3}{*}{0.006} \\
\hline With sarcopenia & 5.00 & $(4,30-5.10)$ & \\
\hline Without sarcopenia ${ }^{a}$ & 5.40 & $(4.90-5.90)$ & \\
\hline Probable sarcopenia ${ }^{a}$ & 5.50 & $(5.00-5.70)$ & \multirow{3}{*}{0.010} \\
\hline Sarcopenia $a^{a, b}$ & 5.10 & $(4.70-5.80)$ & \\
\hline Severe sarcopeniab & 4.60 & $(4.10-5.00)$ & \\
\hline
\end{tabular}

Note: IQ: Interquartile range; Medians followed by the same letter do not differ significantly by the Mann-Whitney test. The severe sarcopenia group differs from the groups: no sarcopenia (0.001) and probable sarcopenia (0.001).

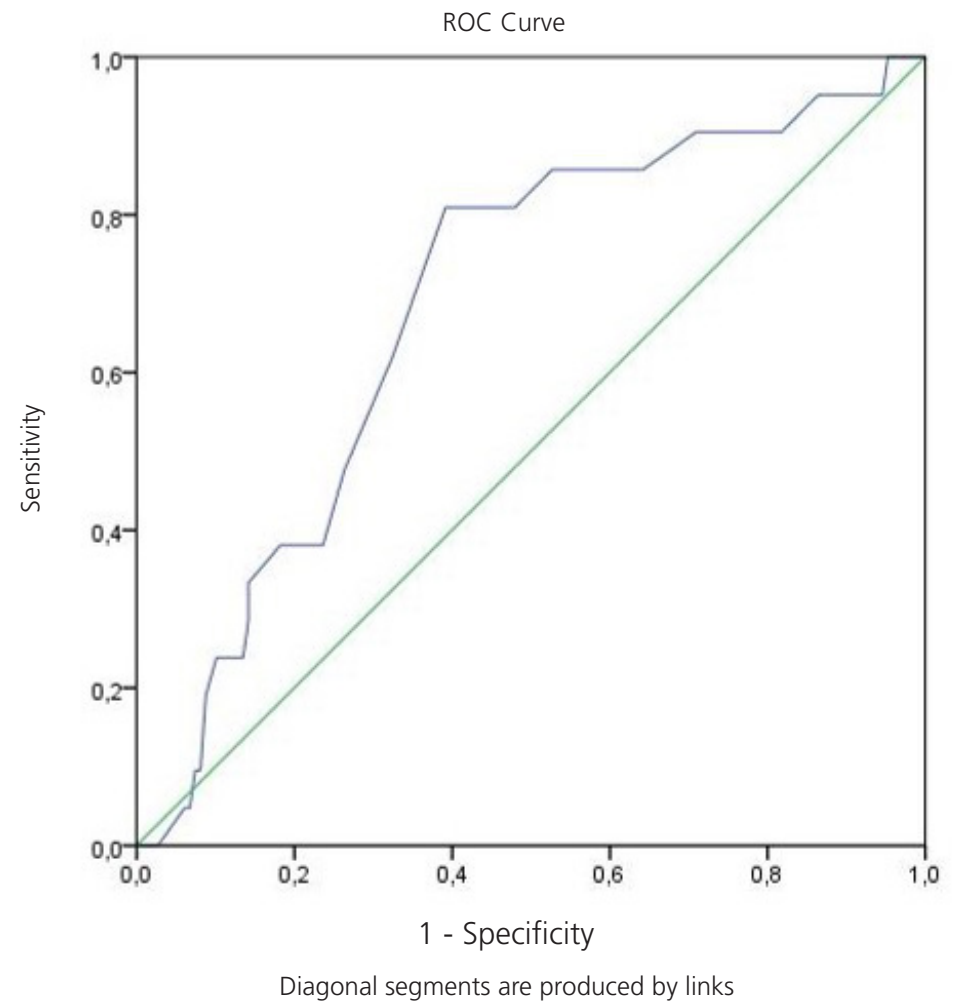

Figura 1 - Receiver Operating Characteristic curve for the phase angle to detect sarcopenia in community-dwelling elderly women. Note: ROC: Receiver Operating Characteristic. The best phase angle cutoff point that showed maximal diagnostic accuracy for sarcopenia was $\leq 5.15^{\circ}$ based on the area under the ROC curve $(0.685 ; 95 \% \mathrm{Cl}: 0.571-0.800)$ with a sens $81.0 \%$ and spec $60.8 \%$.

Logistic regression analysis after adjustment for age and physical activity showed that only muscle mass and sarcopenia were associated with a reduced phase angle $\left(\leq 5.15^{\circ}\right)$. We observed that the risk of reduced muscle mass was approximately three-fold higher and that of sarcopenia was approximately 
five-fold higher in elderly women with a reduced phase angle than in elderly women with a phase angle $>$ the reference value for the detection of sarcopenia (Table 3).

Table 3 - Association between phase angle and sarcopenia and its components.

\begin{tabular}{lcccccc}
\hline Variables & Crude OR & $95 \% \mathrm{IC}$ & $p$ & Adjusted OR & $95 \%$ IC & $p$ \\
\hline Low muscle strength & 1.54 & $0.76-3.09$ & 0.230 & 1.06 & $0.50-2.84$ & 0.872 \\
Low muscle mass & 3.40 & $1.63-7.10$ & 0.001 & 2.54 & $1.17-5.50$ & 0.018 \\
Low physical performance & 2.11 & $1.04-4.26$ & 0.037 & 1.36 & $0.63-2.95$ & 0.430 \\
With sarcopenia & 6.59 & $2.11-20.58$ & 0.001 & 4.69 & $1.44-15.25$ & 0.010 \\
\hline
\end{tabular}

Nota: *Adjusted OR for age and physical activity. OR: Odds Ratio; 95\% IC: 95\% Confidence Intervals.

\section{DISCUSSION}

In this study, the best phase angle cutoff point that showed maximal diagnostic accuracy for sarcopenia was $\leq 5.15^{\circ}$ (sens $84.2 \%$, spec $60.4 \%$ ). This value was higher than that reported by other authors. In a study that included hospitalized and community-dwelling elderly Turkish individuals, Kilic et al. [5] observed a phase angle cutoff value $\leq 4.55^{\circ}$ (area under the ROC curve 0.703 , sens $70 \%$, spec $65.9 \%$ ). Yamada et al. [16] reported a phase angle cutoff value $\leq 3.55^{\circ}$ among community-dwelling elderly Japanese women. These variations may be attributable to differences in ethnicity, age, body mass characteristics, and health status of the populations investigated [6].

The phase angle decreases with aging $[6,8]$ owing to changes in body composition (reduced muscle mass and increased adipose tissue), which occur secondary to changes in body water distribution between tissues, which decreases reactance and increases resistance [17]. Therefore, a reduced phase angle, which indicates reduction in muscle mass and strength (which characterize sarcopenia), serves as a good marker of sarcopenia.

Sarcopenia is diagnosed based on tests that require preserved physical capacity. Therefore, the phase angle can be considered a useful tool to diagnose sarcopenia in elderly patients, particularly in those who cannot perform the tests necessary to evaluate handgrip strength or walking ability. In addition to its role as a determinant of sarcopenia, phase angle measurement serves as a noninvasive and inexpensive BIA-derived method that can be used in clinical practice and epidemiological studies $[5,18]$.

Our study showed that the phase angle was lower in elderly women with sarcopenia than in those without sarcopenia, which is consistent with findings reported by other studies $[5,9,16]$. This observation may be attributable to the association between the phase angle and the parameters that define sarcopenia, specifically the muscle mass, which is positively correlated with the phase angle $[5,9,16,19]$.

Randomized studies that included elderly women who underwent physical training have shown that resistance training performed for muscle development increases the phase angle; this observation reaffirms the correlation between muscle mass and the phase angle [20-22]. In a study performed by Ribeiro et al. [21], physically independent elderly women underwent two types of resistance training; the authors observed an increase in the muscle mass $(20.0-20.4 \mathrm{~kg}$ and $20.2-20.5 \mathrm{~kg}, p<0.05)$ and phase angles $\left(5.60-5.76^{\circ}\right.$ and $\left.5.41-5.63^{\circ}, p<0.05\right)$ after 8-week training. Cunha et al. [22] observed an increased phase angle $\left(5.87-6.12^{\circ}\right.$ and $5.50-5.90^{\circ}$, respectively, $\left.p<0.05\right)$ and improved muscle mass quality, following 12 -week resistance training in elderly women who underwent resistance training compared with elderly women who did not receive this training. 
Although we did not observe an association between the phase angle and muscle strength and physical performance in our study, other studies have reported a correlation between the phase angle and these aforementioned parameters of sarcopenia [5,9,16,23-26].

The convenience nature of the sample and the fact that it is not representative of the Brazilian population are the limitations of our study. Furthermore, BIA is a relatively expensive method, and the results are affected by an individual's hydration status and also pacemaker implantation. Following are the strengths of our study: (a) We used reference values from our study sample itself to diagnose sarcopenia and, (b) we confirmed the utility of the phase angle as a relatively simple and inexpensive screening tool for the diagnosis of sarcopenia.

\section{CONCLUSION}

This study highlights the role of the phase angle as a good predictor of sarcopenia in the population described in this report. The association observed between the phase angle and skeletal muscle mass and sarcopenia strengthens the recommendation for its application as a simple screening tool for diagnosis of sarcopenia to enable early intervention and avoid complications that compromise functional capacity and the quality of life in an aging population.

ACKNOWLEDGEMENTS

The authors thank the study participants and the research team.

CONTRIBUTORS

LB SANTIAGO and LB RAMOS participated in all activities/stages of this research. CC OLIVEIRA contributed to data analysis and interpretation. AKC RORIZ and TM OLIVEIRA contributed to the conception and design of the study, and MEPC MACHADO was actively involved with data interpretation. All authors participated in the review and approval of the final version of the manuscript.

\section{REFERENCES}

1. Cruz-Jentoft AJ, Bahat $G$, Bauer J, Boirie $Y$, Bruyère $O$, Cederholm $T$, et al. Sarcopenia: revised European consensus on definition and diagnosis. Age Ageing. 2019;48(1):16-31. https://doi.org/10.1093/ageing/afy169

2. Peng TC, Chen WL, Wu LW, Chang YW, Kao TW. Sarcopenia and cognitive impairment: A systematic review and meta-analysis. Clin Nutr. 2020;39(9):2695-701. https://doi.org/10.1016/j.clnu.2019.12.014

3. Yeung SSY, Reijnierse EM, Pham VK, Trappenburg MC, Lim WK, Meskers CGM et al. Sarcopenia and its association with falls and fractures in older adults: a systematic review and meta-analysis. J Cachexia Sarcopenia Muscle. 2019;10(3):485-500. https://doi.org/10.1002/jcsm.12411

4. Tsekoura M, Kastrinis A, Katsoulaki M, Billis E, Gliatis J. Sarcopenia and its impact on quality of life. Adv Exp Med Biol. 2017;987:213-8. https://doi.org/10.1007/978-3-319-57379-3_19

5. Kilic MK, Kizilarslanoglu MC, Arik G, Bolayir B, Kara O, Dogan Varan H, et al. Association of bioelectrical impedance analysis-derived phase angle and sarcopenia in older adults. Nutr Clin Pract. 2017;32(1):103-9. https://doi. org/10.1177/0884533616664503

6. Mattiello R, Amaral MA, Mundstock E, Ziegelmann PK. Reference values for the phase angle of the electrical bioimpedance: systematic review and meta-analysis involving more than 250,000 subjects. Clin Nutr. 2020;39(5):1411-7. https://doi.org/10.1016/j.clnu.2019.07.004 
7. Garlini LM, Alves FD, Ceretta LB, Perry IS, Souza GC, Clausell NO. Phase angle and mortality: a systematic review. Eur J Clin Nutr. 2019;73:495-508. https://doi.org/10.1038/s41430-018-0159-1

8. Ferreira AJF, Eickemberg M, Carneiro AKR, Barreto JMB, Ramos LB. Phase angle in institutionalized elderly brazilians. J Nurs Home Res. 2017;3:38-42. https://doi.org/10.14283/jnhrs.2017.6

9. Santana NM, Pinho CPS, Silva CP, Santos NF, Mendes RML. phase angle as a sarcopenia marker in hospitalized elderly patients. Nutr Clin Pract. 2018;33(2):232-7. https://doi.org/10.1002/ncp.10016

10. Alexandre TS, Duarte YA, Santos JL, Wong R, Lebrão ML. Prevalence and associated factors of sarcopenia among elderly in Brazil: findings from the SABE study. J Nutr Health Aging. 2014;18(3):284-90.

11. Baumgartner RN, Chumlea WC, Roche AF. Bioelectric impedance phase angle and body composition. Am J Clin Nutr. 1988;48(1):16-23. https://doi.org /10.1093/ajcn/48.1.16

12. Kyle UG, Bosaeus I, Lorenzo AD, Deurenberg P, Elia M, Gómez JM, et al. Bioelectrical impedance analysis part I: review of principles and methods. Clin Nutr. 2004;23(5):1226-43. https://doi.org/10.1016/j.clnu.2004.06.004

13. Fess EE. Grip strength. In: American Society of Hand Therapists [editor]. Clinical assessment recommendations. 2nd. ed. Garner, NC: Society. 1992;41-5.

14. Janssen I, Heymsfield SB, Baumgartner RN, Ross R. Estimation of skeletal muscle mass by bioelectrical impedance analysis. J Appl Physiol. 2000;89(2):465-71. https://doi.org/10.1152/jappl.2000.89.2.465

15. Lauretani F, Russo CR, Bandinelli S, Bartali B, Cavazzini C, Di lorio A, et al. Age-associated changes in skeletal muscles and their effect on mobility: an operational diagnosis of sarcopenia. J Appl Physiol. 2003;95(5):1851-60. https://doi. org/10.1152/japplphysiol.00246.2003

16. Yamada M, Kimura Y, Ishiyama D, Nishio N, Otobe $Y$, Tanaka T, et al. Phase angle is a useful indicator for muscle function in older adults. J Nutr Health Aging. 2019;23(3):251-5. https://doi.org/10.1007/s12603-018-1151-0

17. Gonzalez MC, Barbosa-Silva TG, Bielemann RM, Gallagher D, Heymsfield SB. Phase angle and its determinants in healthy subjects: influence of body composition. Am J Clin Nutr. 2016;103(3):712-6. https://doi.org/10.3945/ ajcn.115.116772

18. Mulasi U, Kuchnia AJ, Cole AJ, Earthman CP. Bioimpedance at the bedside: current applications, limitations, and opportunities. Nutr Clin Pract. 2015;30(2):180-93. https://doi.org/10.1177/0884533614568155

19. Tomeleri CM, Cavalcante EF, Antunes M, Nabuco HCG, Souza MF, Teixeira DC, et al. Phase angle is moderately associated with muscle quality and functional capacity, independent of age and body composition in older women. J Geriatr Phys Ther. 2019;42(4):281-6. https://doi.org/10.1519/JPT.0000000000000161

20. Souza MF, Tomeleri CM, Ribeiro AS, Schoenfeld BJ, Silva AM, Sardinha LB, et al. Effect of resistance training on phase angle in older women: a randomized controlled trial. Scand J Med Sci Sports. 2017;27(11):1308-16. https://doi.org/ $10.1111 /$ sms. 12745

21. Ribeiro AS, Schoenfeld BJ, Souza MF, Tomeleri CM, Silva AM, Teixeira DC, et al. Resistance training prescription with different load-management methods improves phase angle in older women. Eur J Sport Sci. 2017;17(7):913-21. https://doi.org/10.1080/17461391.2017.1310932

22. Cunha PM, Tomeleri CM, Nascimento MAD, Nunes JP, Antunes M, Nabuco HCG, et al. Improvement of cellular health indicators and muscle quality in older women with different resistance training volumes. J Sports Sci. 2018;36(24):2843-8. https://doi.org/10.1080/02640414.2018.1479103

23. Pessoa DF, Branco FMS, Reis AS, Limirio LS, Borges LP, Barbosa CD, et al. Association of phase angle with sarcopenia and its components in physically active older women. Aging Clin Exp Res. 2020;32:1469-75. https://doi.org/10.1007/ s40520-019-01325-0

24. Bittencourt DCD, Schieferdecker MEM, Macedo DS, Biesek S, Gomes AS, Rabito El. Phase angle reflects loss of functionality in older women. J Nutr Health Aging. 2020;24(3):251-4. https://doi.org/10.1007/s12603-020-1324-5

25. Campa F, Silva AM, Toselli S. Changes in phase angle and handgrip strength induced by suspension training in older women. Int J Sports Med. 2018;39(6):442-9. https://doi.org/10.1055/a-0574-3166

26. Matias CN, Nunes CL, Francisco S, Tomeleri CM, Cyrino ES, Sardinha LB, et al. Phase angle predicts physical function in older adults. Arch Gerontol Geriatr. 2020;90:104151. https://doi.org/10.1016/j.archger.2020.104151 